\title{
Associated congenital anomalies between neonates with short-gap and long-gap esophageal atresia: a comparative study
}

This article was published in the following Dove Press journal:

International Journal of General Medicine

22 June 2011

Number of times this article has been viewed

\author{
Saeid Aslanabadi' \\ Kamyar Ghabili² \\ Mohsen Rouzrokh ${ }^{3}$ \\ Mohammad Bagher \\ Hosseini' \\ Masoud Jamshidi' \\ Farzad Hami Adl ${ }^{4}$ \\ Mohammadali M Shoja ${ }^{5}$ \\ 'Pediatric Health Research Center, \\ Tabriz University of Medical Sciences, \\ Tabriz; ${ }^{2}$ Tuberculosis and Lung Disease \\ Research Center, Tabriz University of \\ Medical Sciences, Tabriz; ${ }^{3}$ Department \\ of Pediatric Surgery, Mofid Hospital, \\ Shaheed Beheshti University of \\ Medical Sciences, Tehran; ${ }^{4}$ Faculty \\ of Medicine, Tabriz University of \\ Medical Sciences, Tabriz; ${ }^{5}$ Tuberculosis \\ and Lung Disease Research Center, \\ Tabriz University of Medical Sciences, \\ Tabriz, Iran
}

Background: Predicting the presence of long-gap esophageal atresia (EA) prior to the surgery is of clinical importance. No comparison between short-gap and long-gap EA for the prevalence of VACTERL and non-VACTERL-type anomalies has yet been performed.

Objective: The aim of this study was to compare VACTERL and non-VACTERL-type anomalies between patients with short-gap and long-gap EA.

Methods: Retrospectively, medical records of all newborns managed for EA/tracheoesophageal fistula (TEF) in Tabriz Children's Hospital and Tehran Mofid Hospital between 2007 and 2010 were evaluated. Demographic data and associated anomalies including both the VACTERL and non-VACTERL-type defects were listed. The VACTERL spectrum defects covered vertebral/costal, anorectal, cardiovascular, TEF, and renal- or radial-type limb anomalies. The non-VACTERL-type anomalies included hydrocephalus, orofacial defects, respiratory system anomalies, gastrointestinal anomalies, genital anomalies, and non-VACTERL limb defects. Demographic data, and the VACTERL and non-VACTERL-type anomalies were compared among children with long-gap EA and those with short-gap EA.

Results: Two hundred and seventy-six children were included in the study: $230(83.3 \%)$ in the short-gap EA group and 46 (16.7\%) in the long-gap EA group. Although prevalence of the VACTERL spectrum anomalies did not differ between the two groups, the non-VACTERL anomaly was more common in the long-gap EA group $(P=0.02)$. Among the VACTERL-type defects, TEF was detected in $30(65.2 \%)$ and 218 (94.7\%) patients in long-gap and short-gap EA groups, respectively $(P=0.0001)$

Conclusion: The non-VACTERL-type anomalies, but not the VACTERL spectrum defects, are more frequent in patients with long-gap EA than those with short-gap EA.

Keywords: esophageal atresia, short-gap, long-gap, tracheoesophageal fistula, anomaly, VACTERL

\section{Introduction}

Esophageal atresia (EA), a rare congenital anomaly, occurs as an isolated entity or in association with tracheoesophageal fistula (TEF). ${ }^{1}$ Depending on the size of gap between esophageal ends, EA is divided into short-gap and long-gap EA. The latter, accounting for $10 \%$ to $31 \%$ of EA cases, is described by a significant gap between the esophageal ends, making repair more aggressive. ${ }^{2,3}$ The gap length not only determines the type of surgical management, but also is a prognostic indicator of mortality and morbidity in EA patients. ${ }^{2,4}$ However, long-gap EA is often identified in the course of thoracotomy and may pose further unexpected challenges for operating surgeons. ${ }^{5}$ Therefore, predicting the presence of long-gap EA prior to the surgery seems to be of utmost importance.
Correspondence: Kamyar Ghabili Tuberculosis and Lung Disease Research Center, Tabriz University of Medical Sciences, Tabriz, Iran

$\mathrm{Tel}+989144106136$

$\mathrm{Fax}+984113363846$

Email kghabili@gmail.com 
The embryologic defects leading to EA are associated with varying components of the malformation association termed VACTERL. ${ }^{6}$ VACTERL association describes vertebral defects, anorectal malformation, cardiac anomalies, TEF and/or EA, renal anomalies, and limb defects. ${ }^{7,8}$ Although controversial, some authorities attributed specific congenital anomalies to the presence of long-gap EA. Canty et al first indicated that aortic arch anomalies were associated with long-gap EA/TEF. ${ }^{9}$ Moreover, although not statistically investigated, Kulkarni and coworkers noted that, interestingly, 13 pairs of ribs were present in three-fourths of patients with long-gap EA, while none of those with short-gap EA had such a skeletal anomaly. ${ }^{5}$ Later study by Bosenberg and Hadley failed to confirm the indicated association between the long-gap EA and 13 ribs in neonates presenting with EA/TEF. ${ }^{10}$ On the other hand, Gupta et $\mathrm{al}^{11}$ investigated the size of gap between the pouches in patients with 13 pairs of ribs, right-sided aortic arch, and azygos vein anomaly and their corresponding controls. They found that the mean gap did not differ between neonates with 13 pairs of ribs and those with 12 pairs of ribs. However, the mean gap was significantly higher in both right-sided aortic arch and azygos-vein anomaly groups than in their normal controls. ${ }^{11}$ Nevertheless, to the best of our knowledge, no comparison between the short-gap and long-gap EA for the prevalence of the VACTERL and non-VACTERL-type anomalies has been yet performed. Therefore, we aimed to compare EA-associated anomalies, both VACTERL and non-VACTERL type, between patients with the short-gap and long-gap EA.

\section{Methods and materials}

Ethical approval was obtained from the Medical Ethics Committee of the Tabriz University of Medical Sciences. Retrospectively, medical records of all newborns managed for EA/TEF in Tabriz Children's Hospital and Tehran Mofid Hospital between 2007 and 2010 were reviewed. The pediatric surgery departments of these university-affiliated hospitals are tertiary referral centers for pediatric surgery in Northwestern and the capital of Iran, respectively. ${ }^{12,13}$ All infants with EA/TEF born in the indicated areas are admitted to either of the two hospitals. Both centers keep comprehensive databases on cases with EA/TEF, including data on associated anomalies, pregnancy history, and postnatal clinical course. Demographic data including gestational age, delivery status (term or preterm delivery), type of delivery (normal vaginal delivery or cesarean section), birth weight, and gender were collected. In addition, associated anomalies including both the VACTERL- and non-VACTERL-type defects were listed. Defects of the VACTERL spectrum covered vertebral anomalies (including costal anomalies), anorectal malformations, cardiovascular malformations, TEF (distal and/or proximal), renal anomalies, or radial-type limb anomalies. ${ }^{14}$ Diagnosis of the VACTERL association was defined as the presence of EA and at least two combined defects of the VACTERL spectrum including vertebral, anorectal, cardiovascular, and renal- or radial-type limb anomalies. ${ }^{15}$ Moreover, the non-VACTERL-type defect was defined if any of these anomalies was present: hydrocephalus, orofacial defects (cleft lip/palate, supernumerary nostril, and tongue-tie), respiratory system anomalies (choanal atresia, laryngeal anomalies, lung hypoplasia, and diaphragmatic hernia), gastrointestinal anomalies (duodenal atresia, intestinal malrotation, hypertrophic pyloric stenosis, and annular pancreas), genital anomalies (undescended testis, hypospadias, and ambiguous genitalia), and non-VACTERL limb defects, eg, lower limb anomalies. ${ }^{14}$ During the study period (2007-2010), all the VACTERL and non-VACTERL components were assessed with the same criteria for all the newborns managed for EA/TEF.

In this study, EA patients were considered to have longgap EA when primary end-to-end anastomosis was not feasible due to the length of the gap between the proximal and distal ends of the esophagus; or anastomosis was performed with tension; or other surgical techniques including gastric pull up and/or cervical esophagostomy were performed. ${ }^{16-19}$ Considering the present investigation as a case-control study, the cases and controls were patients with long-gap and short-gap EA, respectively. The independent variable was the VACTERL- and non-VACTERL-type anomalies. Demographic data and the VACTERL- and non-VACTERLtype anomalies were compared between children with longgap EA and those with short-gap EA.

Data are presented as mean \pm standard deviation (SD) or percentage. Statistical analysis was performed with SPSS for Windows (v 16.0, Chicago, IL) by using Chi-square test, Fisher's exact test, and independent-samples $t$-test wherever appropriate. To express the strength of a significant association, odds ratio (OR) between the outcomes of the two groups is presented and $95 \%$ confidence intervals $(\mathrm{CI})$ are reported. A $P<0.05$ was considered statistically significant.

\section{Results}

Two hundred and seventy-six children were included in the study: $230(83.3 \%)$ in the short-gap EA group and $46(16.7 \%)$ in the long-gap EA group. Patients with long-gap EA were 
born at earlier gestational age $(P=0.001)$, were more often delivered by cesarean section $(P=0.01)$, and had lower birth weight $(P=0.0001)$. The patients' characteristics and associated anomalies are shown in Table 1 . Of 276 patients with EA, 197 (71.3\%) patients had two or more VACTERL-type defects. In contrast, non-VACTERL anomalies were detected in $35(12.6 \%)$ patients with EA.

Although prevalence of the VACTERL spectrum anomalies did not differ between the two groups, the nonVACTERL anomaly was more common in long-gap EA group $(P=0.02$, Table 1$)$. Among the VACTERL-type defects, TEF was detected in $30(65.2 \%)$ and $218(94.7 \%)$ patients in long-gap and short-gap EA groups, respectively (Table $1, P=0.0001$, Fisher's exact test).

\section{Discussion}

The study revealed that prevalence of the VACTERL spectrum anomalies was comparable between patients with short-gap and long-gap EA. This finding is consistent with that of the study by Lopes and Botelho disclosing comparable prevalence of associated VACTERL type anomalies between short-gap and long-gap EA. ${ }^{2}$ Although Al-Shanafey and Harvey ${ }^{18}$ and Bagolan et $\mathrm{al}^{20}$ found similar results, they did not specify whether they studied the VACTERL-type anomalies. Furthermore, non-VACTERL-type anomalies were associated with long-gap EA in the present study.
In our series of neonates, an infant with a non-VACTERL anomaly was almost three times as likely to have an associated long-gap EA. However, we do not have an explanation for this finding in the present study. In addition, patients with long-gap EA had less TEF than those with short-gap EA. This finding, although still in debate, is considered as a definition of long-gap EA by some pediatric surgeons. ${ }^{18}$ To the best our knowledge, the present study is the first investigation to compare the detailed anomalies, both the VACTERL and non-VACTERL anomalies, between long-gap and short-gap EA patients.

First introduced by Quan and Smith in 1973, VATER association described vertebral defects, anorectal malformation, TEF and/or EA, renal anomalies, and radial dysplasia. ${ }^{7}$ Later, cardiac and limb defects were included, hence the VACTERL acronym. ${ }^{8}$ Although the underlying etiology of the VACTERL association is still unclear, chromosomal anomalies and environmental exposures have been deemed to play etiologic roles. ${ }^{6,14}$ Full or partial VACTERL spectrum defects have been reported in $24 \%$ to $67 \%$ of the neonates with EA/TEF. ${ }^{14,21-23}$ Almost similar to this range, we found the VACTERL association in $71 \%$ of the studied population. Excluding TEF in both short- and long-gap EA groups, the cardiovascular anomalies, followed by the vertebral defects, were most common among the VACTERL spectrum anomalies. This trend has been previously reported by

Table I Demographic data and associated anomalies for patients with short-gap vs long-gap esophageal atresia (mean \pm SD) ( $\mathrm{n}=$ number of patients)

\begin{tabular}{|c|c|c|c|c|}
\hline Characteristics & $\begin{array}{l}\text { Short-gap group } \\
(n=230)\end{array}$ & $\begin{array}{l}\text { Long-gap group } \\
(n=46)\end{array}$ & $\begin{array}{l}\text { Odds ratio } \\
(95 \% \mathrm{Cl})\end{array}$ & P-value \\
\hline Gender (male:female) & $128: 102$ & 29:17 & $0.73(0.38-1.42)$ & 0.41 \\
\hline Gestational age (weeks) & $36.5 \pm 1.8$ & $34.7 \pm 2.3$ & - & $0.00 I^{*}$ \\
\hline Birth weight (g) & $2727.8 \pm 575.5$ & $2288.6 \pm 565.1$ & - & $0.0001 *$ \\
\hline Type of delivery (NVD:CS) & $(130: 100)$ & $(16: 30)$ & $2.48(1.15-5.37)$ & $0.02 *$ \\
\hline Preterm delivery: n (\%) & $73(31.7 \%)$ & $33(71.7 \%)$ & $0.18(0.05-0.55)$ & $0.003 *$ \\
\hline VACTERL-type anomalies & 168 (73\%) & $29(63 \%)$ & $0.63(0.32-1.22)$ & 0.21 \\
\hline Vertebral anomalies: n (\%) & $33(14.3 \%)$ & $8(17.3 \%)$ & $1.85(0.67-5.10)$ & 0.26 \\
\hline Anorectal malformation: n (\%) & $18(7.8 \%)$ & $5(10.8 \%)$ & $1.43(0.50-4.06)$ & 0.55 \\
\hline Cardiovascular anomalies: n (\%) & $160(69.5 \%)$ & $36(78.2 \%)$ & $2.56(0.96-6.85)$ & 0.07 \\
\hline Tracheoesophageal fistula: $n(\%)$ & $218(94.7 \%)$ & $30(65.2 \%)$ & $0.10(0.04-0.23)$ & $0.000 I^{*}$ \\
\hline Renal anomalies: n (\%) & $22(9.5 \%)$ & $7(15.2 \%)$ & $2.27(0.86-5.96)$ & 0.14 \\
\hline Radial/upper limb anomalies: n (\%) & $8(3.4 \%)$ & $\mathrm{I}(2.1 \%)$ & $0.61(0.07-5.03)$ & 1.00 \\
\hline Non-VACTERL-type anomalies & $24(10.4 \%)$ & I I (23.9\%) & $2.69(1.21-5.99)$ & $0.02 *$ \\
\hline Hydrocephalus: n (\%) & $2(0.8 \%)$ & I (2.l\%) & $2.5 \mathrm{I}(0.22-28.28)$ & 0.42 \\
\hline Orofacial anomalies: n (\%) & $3(1.3 \%)$ & $2(4.3 \%)$ & $3.40(0.55-2 I)$ & 0.19 \\
\hline Respiratory system anomalies: n (\%) & $10(4.3 \%)$ & $0(0)$ & $0.82(0.78-0.87)$ & 0.15 \\
\hline Gastrointestinal anomalies: n (\%) & $4(1.7 \%)$ & $2(4.3 \%)$ & $2.55(0.45-14.39)$ & 0.26 \\
\hline Genital anomalies: n (\%) & $4(1.7 \%)$ & $2(4.3 \%)$ & $2.55(0.45-14.39)$ & 0.26 \\
\hline Non-VACTERL limb anomalies: $n$ (\%) & $7(3 \%)$ & $4(8.6 \%)$ & $3.02(0.84-10.77)$ & 0.09 \\
\hline
\end{tabular}

Note: *Statistically significant $(P<0.05)$.

Abbreviations: NVD, normal vaginal delivery; CS, cesarean section. 
Keckler and colleagues. ${ }^{6}$ Nonetheless, de Jong et al ${ }^{14}$ found an inverse trend; the vertebral defects were most common, followed by the cardiovascular anomalies. Such a discrepancy might be attributed to variations in definition of the cardiac anomalies, ie, intrinsic vs extrinsic heart lesions.

The non-VACTERL anomalies have been reported in $20 \%$ to $70 \%$ of EA patients in the previous investigations. ${ }^{14,22,24,25}$ In the present study, we found the non-VACTERL-type anomalies in approximately $13 \%$ of the EA patients with or without TEF. Among the non-VACTERL-type anomalies, the respiratory system anomalies and the non-VACTERL limb defects were the most prevalent in short-gap and long-gap EA groups, respectively. The former occurred frequently $(33.3 \%)$ among 15 EA patients studied by Yang and coworkers. ${ }^{24}$ Nevertheless, the corresponding figures reported by other authors are much closer to our findings. ${ }^{14,25}$ An association of EA and the respiratory tract anomalies may imply a defective development of the foregut, a segment from which both the esophagus and the respiratory system develop in the fetus. ${ }^{14}$ Such an association has been previously demonstrated in animal studies. ${ }^{26,27}$

The present study demonstrated that patients with longgap EA were born at earlier gestational age. This finding is consistent with that of the studies by Al-Shanafey and Harvey ${ }^{18}$ and Lopes and Botelho. ${ }^{2}$ In contrast, Bagolan and colleagues failed to find any difference between the two groups in gestational age. ${ }^{20}$ Similar to the study by Lopes and Botelho, ${ }^{2}$ we found that patients with long-gap EA had lower birth weight and were more premature than the shortgap EA group.

This study has certain limitations. We applied a pragmatic definition of long-gap EA rather than a numerical definition. Moreover, the retrospective nature of this report could affect the validity of the data. On the other hand, some advantages of the current study might be highlighted. Only two pediatric surgeons (S Aslanabadi and M Rouzrokh) have managed our patients. This could minimize classification bias. Furthermore, associated congenital anomalies were accurately separated for the VACTERL and non-VACTERL anomalies in a large number of EA patients.

In conclusion, the non-VACTERL-type anomalies, but not the VACTERL spectrum defects, are more frequent in patients with long-gap EA than in those with short-gap EA. Furthermore, patients with long-gap EA are born at earlier gestational age, are delivered more by cesarean section, and have lower birth weight. Further investigations are needed to determine the predictors of long-gap EA/TEF prior to the surgical intervention.

\section{Acknowledgment}

This study was financially supported by a grant from the Tuberculosis and Lung Disease Research Center, Tabriz University of Medical Sciences. This paper is based on Kamyar Ghabili's MD dissertation (89/1-13/29) submitted to the Faculty of Medicine, Tabriz University of Medical Sciences, Tabriz, Iran.

\section{Disclosure}

The authors report no conflicts of interest in this work.

\section{References}

1. Aslanabadi S, Jamshidi M, Tubbs RS, Shoja MM. The role of prophylactic chest drainage in the operative management of esophageal atresia with tracheoesophageal fistula. Pediatr Surg Int. 2009;25:365-368.

2. Lopes MF, Botelho MF. Midterm follow-up of esophageal anastomosis for esophageal atresia repair: long-gap versus non-long-gap. Dis Esophagus. 2007;20:428-435.

3. Lai JY, Sheu JC, Chang PY, Yeh ML, Chang CY, Chen CC. Experience with distal circular myotomy for long-gap esophageal atresia. J Pediatr Surg. 1996;31:1503-1508.

4. Brown AK, Tam PK. Measurement of gap length in esophageal atresia: a simple predictor of outcome. J Am Coll Surg. 1996;182:41-45.

5. Kulkarni B, Rao RS, Oak S, Upadhyaya MA. 13 pairs of ribs a predictor of long gap atresia in tracheoesophageal fistula. $J$ Pediatr Surg. 1997;32:1453-1454.

6. Keckler SJ, St Peter SD, Valusek PA, et al. VACTERL anomalies in patients with esophageal atresia: an updated delineation of the spectrum and review of the literature. Pediatr Surg Int. 2007;23:309-313.

7. Quan L, Smith DW. The VATER association. Vertebral defects, Anal atresia, T-E fistula with esophageal atresia, Radial and Renal dysplasia: a spectrum of associated defects. J Pediatr. 1973;82:104-107.

8. Nora AH, Nora JJ. A syndrome of multiple congenital anomalies associated with teratogenic exposure. Arch Environ Health. 1975;30:17-21.

9. Canty TG Jr, Boyle EM Jr, Linden B, et al. Aortic arch anomalies associated with long gap esophageal atresia and tracheoesophageal fistula. J Pediatr Surg. 1997;32:1587-1591.

10. Bosenberg AT, Hadley GP. Association between long gap atresia and 13 ribs in neonates presenting with esophageal atresia and tracheoesophageal fistula. J Pediatr Surg. 1998;33:1328.

11. Gupta DK, Arora M, Srinivas M. Azygos vein anomaly: the best predictor of a long gap in esophageal atresia and tracheoesophageal fistula. Pediatr Surg Int. 2001;17:101-103.

12. Ghorashi Z, Nezami N, Ghalehgolab Behbahan A, Ghorashi S. Supplemental food may not prevent iron-deficiency anemia in infants. Indian J Pediatr. 2008;75:1121-1124.

13. Naderpour M, Mortazavi F, Jabbari-Moghaddam Y, SharifiMovaghar MH. Auditory brain stem response and otoacoustic emission results in children with end-stage renal disease. Int $J$ Pediatr Otorhinolaryngol. 2011;75:704-707.

14. de Jong EM, Felix JF, Deurloo JA, et al. Non-VACTERL-type anomalies are frequent in patients with esophageal atresia/tracheo-esophageal fistula and full or partial VACTERL association. Birth Defects Res A Clin Mol Teratol. 2008;82:92-97.

15. Seo J, Kim do Y, Kim AR, et al. An 18-year experience of tracheoesophageal fistula and esophageal atresia. Korean J Pediatr. 2010;53:705-710

16. Mansur SH, Talat N, Ahmed S. Oesophageal atresia: role of gap length in determining the outcome. Biomedica. 2005;21:125-128.

17. Ron O, De Coppi P, Pierro A. The surgical approach to esophageal atresia repair and the management of long-gap atresia: results of a survey. Semin Pediatr Surg. 2009;18:44-49. 
18. Al-Shanafey S, Harvey J. Long gap esophageal atresia: an Australian experience. J Pediatr Surg. 2008;43:597-601.

19. Hunter CJ, Petrosyan M, Connelly ME, et al. Repair of long-gap esophageal atresia: gastric conduits may improve outcome-a 20-year single center experience. Pediatr Surg Int. 2009;25:1087-1091.

20. Bagolan P, Iacobelli Bd B, De Angelis P, et al. Long gap esophageal atresia and esophageal replacement: moving toward a separation? J Pediatr Surg. 2004;39:1084-1090.

21. Botto LD, Khoury MJ, Mastroiacovo P, et al. The spectrum of congenital anomalies of the VATER association: an international study. Am J Med Genet. 1997;71:8-15.

22. Khoury MJ, Cordero JF, Greenberg F, James LM, Erickson JD. A population study of the VACTERL association: evidence for its etiologic heterogeneity. Pediatrics. 1983;71:815-820.
23. Weaver DD, Mapstone CL, Yu PL. The VATER association. Analysis of 46 patients. Am J Dis Child. 1986;140:225-229.

24. Yang CF, Soong WJ, Jeng MJ, et al. Esophageal atresia with tracheoesophageal fistula: ten years of experience in an institute. J Chin Med Assoc. 2006;69:317-321.

25. Czeizel A, Telegdi L, Tusnády G. VACTERL-association. In: Czeizel A, Telegdi L, Tusnády G, editors. Multiple Congenital Anomalies. Budapest: Akadémiai Kiadó; 1988:247-280.

26. Minoo P, Su G, Drum H, Bringas P, Kimura S. Defects in tracheoesophageal and lung morphogenesis in Nkx2.1(-/-) mouse embryos. Dev Biol. 1999;209:60-71.

27. Motoyama J, Liu J, Mo R, Ding Q, Post M, Hui CC. Essential function of Gli2 and Gli3 in the formation of lung, trachea and oesophagus. Nat Genet. 1998;20:54-57.
International Journal of General Medicine

\section{Publish your work in this journal}

The International Journal of General Medicine is an international peer-reviewed open-access journal that focuses on general and internal medicine, pathogenesis, epidemiology, diagnosis, monitoring and treatment protocols. The journal is characterized by the rapid reporting of reviews, original research and clinical studies across all disease areas.

\section{Dovepress}

A key focus is the elucidation of disease processes and management protocols resulting in improved outcomes for the patient.The manuscript management system is completely online and includes a very quick and fair peer-review system. Visit http://www.dovepress.com/ testimonials.php to read real quotes from published authors.

Submit your manuscript here: http://www.dovepress.com/international-journal-of-general-medicine-journal 